\title{
Feasibility study for genetic testing and SNP analysis in infants
}

\author{
Madalynn Neu ${ }^{1}$, Marisa Ehringer ${ }^{2}$, Cassandra Marcheggiani-Howard ${ }^{1}$ \\ ${ }^{1}$ College of Nursing, University of Colorado, Aurora Colorado, USA \\ ${ }^{2}$ Institute of Behavioral Genetics, University of Colorado, Boulder Colorado, USA \\ Email: madalynn.neu@ucdenver.edu, Marissa.Ehringer@colorado.edu, cassmarche@yahoo.com
}

Received 30 November 2013; revised 31 December 2013; accepted 21 January 2014

Copyright (C 2014 Madalynn Neu et al. This is an open access article distributed under the Creative Commons Attribution License, which permits unrestricted use, distribution, and reproduction in any medium, provided the original work is properly cited. In accordance of the Creative Commons Attribution License all Copyrights (c) 2014 are reserved for SCIRP and the owner of the intellectual property Madalynn Neu et al. All Copyright (C) 2014 are guarded by law and by SCIRP as a guardian.

\section{ABSTRACT}

Purpose: Determine whether parents would consent to genotyping for temperament characteristics for their infants; establish that quality DNA is obtained from infants using a cheek swab. Design and Methods: Seventeen mother-father dyads and infants, 11 to 35 weeks of age, who had participated in a GERD (gastroesophageal reflux disease) massage study participated in this feasibility study. Results: Seventy-one percent of parents agreed to genotyping. Most parents who participated were concurrently enrolled in the GERD massage study. Reasons provided for participating were support of research and the desire to help other families who had infants with GERD. Parents who participated also had higher educational attainment than those who declined. Reasons for declining were dislike of genetic research. All samples could be analyzed. Practice Implications. Many parents allowed genotyping, especially if currently engaged with research staff. Cheek swabs are a noninvasive and satisfactory method of DNA collection.

\section{KEYWORDS}

\section{DNA; Infants; Temperament; Parent Consent}

\section{INTRODUCTION}

Gastroesophageal reflux (GER), is the involuntary regurgitation of gastric contents into the esophagus and is common in infants. However, about one in four infants experience the more complicated form of GER, gastroesophageal reflux disease, called GERD [1]. GERD is characterized by frequent regurgitation, heightened irritability, and feeding difficulties, sometimes accompanied by back arching, cyanosis, and apnea [2]. The symptom of irritability can result from a number of causes. Discomfort from acid reflux certainly is likely, but infant crying and fussing have been shown to occur with bouts of both acid and nonacid reflux [3]. Thus, some infants may not experience pain with reflux but may perceive the sensation of reflux as discomforting. Anti-reflux medications relieve acid reflux but are not more effective than placebo in reducing crying in infants with GERD [4-6], suggesting that infant temperament characteristics, such as negativity (i.e. fussiness and crying) and tolerance of discomfort, might play a role in irritability in infants with GERD. Several genes are reported to be associated with these temperament characteristics in infants: dopamine D4 receptor (gene symbol: $D R D 4$ ), dopamine transporter (gene symbol: DAT), Catechol-OMethyltransferase (gene symbol: COMT), and the serotonin transporter (5-HTT, 5-hydroxytryptomine, gene symbol: SLC6A4) [7-11].

Before embarking on a large-scale genetic study investigating temperament genes in infants with GERD, our research team conducted a feasibility study. Feasibility studies often are necessary to determine whether a study can be conducted. Parameters of a feasibility study include willingness of participants to consent to the study, number of eligible participants that can be enrolled, designing a suitable outcome measure, and usability of data [12]. We designed the feasibility study to validate design and protocol for obtaining parental consent, and collecting and genotyping DNA from infants using buccal swabs.

\section{GENETIC TESTING}

\subsection{Potential Barriers to Parental Consent for Genetic Testing for Their Infants}

Parents face complex ramifications when deciding to 
have their infant's DNA genotyped, creating possible barriers to consent. An obvious issue is that their infants cannot decide if they want their DNA genotyped. The parent must make the decision based on what they consider is in the best interest of the infant at the time they are consenting.

One potential barrier is that findings of this study would not lead to immediate diagnosis or treatment. Guidelines addressing genetic testing of minors clearly advocate that the main justification for testing is whether treatment is available [13]. Parents seem to support these guidelines. For example, when Danish parents $(n=397)$ were asked if they would participate in genetic research for their children related to risks for mental health disorders, only $30 \%$ said they would consent if no treatment was available [14]. Parents have expressed frustration and disappointment when genetic evaluation and testing leads to lack of a clear diagnosis or cause [15].

A second potential barrier is that parents would not be provided with individual genetic results of this feasibility study. Botkin [16] admonished that the purpose of research is not to provide results to individual participants but to advocate science and further asserted that when considering the disclosure of results to individual participants, the most important question is whether the information generated in the research has clinical significance [16]. When research is in the exploratory stages, reporting results to the parents may not be beneficial. Nevertheless, mothers have expressed that they want individual results of genetic studies of their children [15].

Lack of trust in researchers is a third potential barrier to consenting. Twenty-eight percent of mothers of newborns $(n=177)$ mentioned fear that researchers would use the genetic samples for research other than what was specified in the consent, and that the researchers would not keep findings of the analysis of the samples confidential [17]. Jenkins et al. [15] also found maternal fear of disclosure of genetic findings.

Parental stress, especially in mothers, may be an additional barrier to consent for genetic research. Mothers of infants with GERD have been reported to be more frustrated and angry with their infants and believe that they are more problematic and demanding than mothers of other infants [18]. Our research team was therefore concerned that mothers (and fathers) trying to cope with an infant with GERD may agree to participate in a study providing an intervention to decrease GERD symptoms, but may be less willing to allow time for a study that had no potential for immediately helping the infants.

\subsection{DNA Sampling Techniques in Infants}

Collection of DNA using buccal swabs offers advantages to blood sampling and swabs are being used more fre- quently because of the ease of collection and lack of discomfort [19]. Buccal cells are obtained by rotating a soft cotton swab or stiffer brush in the cheek of the infant. The swabs are then stored in solutions in which the DNA remains stable for many years [19]. Parents or nonmedical research assistants are capable of collecting buccal samples, but need training. In one study, mothers of 39 infants collected DNA at home using buccal swabs and returned samples by mail. Eleven percent of the samples could not be genotyped due to low cell counts. To maximize the potential of collecting an adequate amount of DNA, thorough training in collection methods is necessary [20]. Another possible disadvantage to buccal swab collection is that they may yield insufficient quantity for studies examining multiple genes [21].

The aims of this study were to 1 ) to determine whether parents would consent to have DNA collected by cheek (buccal) swab from their infants for genotyping for temperament characteristics, and 2) to establish that an adequate amount of DNA could be obtained from infant buccal swabs for genotyping the four genes of interest.

\section{MATERIALS AND METHODS}

This feasibility study was done with parents from an existing six-week GERD intervention study using massage therapy. Buccal swabs were obtained from a subsample of infants who were a part of this study. The massage intervention study was a randomized control trial with a goal of 34 infants. Infants were 4 to 12 weeks at enrollment, healthy at birth, and diagnosed with GERD by the infant's pediatric provider. Infants were ineligible if; they required major surgery, had a chronic illness other than GERD, a congenital anomaly, symptoms of cow's milk allergy, or bilious or projectile vomiting

\subsection{Sample and Recruitment}

Recruitment for this feasibility study occurred from two groups, parents of infants who had completed the massage study for GERD (COMPL) and used directly for the production of any commercial product b) reports about the research done with their infant's sample would not be kept in the infant's health records, but could be kept with the study records or in other secure areas; c) the saliva sample would be de-identified; and d) they would not be informed of the results of the research.

Mothers also were told that the genetic study was a feasibility study to determine if adequate DNA could be collected from infants to examine four genes associated with temperament. Parents were told that if these genes could assist in early identification of infants who might show irritability with reflux (GER), potential preventive care addressing temperament could be developed that might lessen the irritability. The procedure for DNA col- 
lection using buccal swabs was explained. Mothers were informed that the DNA would be destroyed after genotyping and that they would not receive individualized information about the findings from this genetic study on temperament.

\subsection{DNA Procedures Collection}

All identifying information was collected by the research team. Only members of that team had access to identifying information. Subject IDs were assigned to all genetic data, which was linked with laboratory IDs. The PI (MN) was blinded to the genetic data associated with a subject ID, and the geneticist (ME) and laboratory assistant were blinded to any identifying information (name, birth date etc.).

Three research assistants (RAs), who were nursing students, were trained to collect the DNA using buccal swabs in an in-house kit that the geneticist has used successfully with older children. To avoid contamination, the samples were obtained using sterile technique. All DNA samples were obtained in the homes of the infants. While the RA explained the genetic consent to parents, she interacted with the infant as much as possible before collecting the DNA. The mother was present while the DNA was obtained. To insure that an adequate amount of buccal cells were obtained, two separate swabbings were done. Each collection consisted of having the infant suck briefly on the swab (to moisten the swab), then the RA gently rolled the swab against the inside of the infant's cheek to obtain cheek cells. The two swabs for each infant were placed immediately in a plastic tube containing a lysis solution to insure stability of the DNA until it was genotyped. This method has been used previously by our group with adult sampling [22]. Samples were stored at room temperature. No special storage was needed. DNA collection was conducted from April through August, 2011 and genotyping was completed in September 2011. DNA was isolated using a standard alkaline-lysis protocol. DNA concentrations were determined using a Qubit Fluorometer and PicoGreen assays. DNA recovery amounts ranged from $120 \mathrm{ng}$ to $3.2 \mathrm{ug}$, which is typical for buccal swab collections.

\subsection{Protocol for SNP Genotyping}

TaqMan assays were used for SNP genotyping according to the manufacturer's instructions (Applied Biosystems, Foster City, California) previously described by Hoft, et al. [23]. Polymerase Chain Reaction (PCR) reactions were set up with a Biomek ${ }^{\circledR} 3000$ Laboratory Automation Workstation (Beckman Coulter Inc, Brea, California) and cycled in an ABI GeneAmp ${ }^{\circledR} 9700$ PCR thermocycler (Applied Biosystems, Foster City, California) or ABI PRISM $^{\circledR} 7900$ thermocycler (Applied Biosystems, Foster
City, California). Standard cycling parameters were used: $50^{\circ} \mathrm{C}$, a $95^{\circ} \mathrm{C}$ hot start, followed by 50 cycles of $92^{\circ} \mathrm{C}$ for 15 seconds, $60^{\circ} \mathrm{C} 1$ minute, and then $4^{\circ} \mathrm{C}$ hold. The ABI PRISM $^{\circledR} 7900$ was used to analyze PCR products. Initially, the genotype clusters were identified automatically by the Applied Biosystems TaqMan ${ }^{\circledR}$ Genotyper software (Applied Biosystems, Foster City, California), then independently validated by two genetic technicians DNA samples with overall call rates $<90 \%$ (failed on $>10 \%$ of the SNPs genotyped) were excluded. Since there were very few samples in this study, we used in-house control DNAs from another project in order to run 96 samples together and thus provide improved clustering. At least three wells containing only water were included on each plate.

\section{RESULTS}

\subsection{Sample}

Mean age of infants at the time of DNA collection was 10.2 months $(\mathrm{SD}=0.9)$ in the COMPL and 11.9 weeks $(\mathrm{SD}=2.6)$ in the ENROL group. Ethnicity of the infants was European/American except for two infants whose fathers were Asian and one whose father was Hispanic. Characteristics of parents who consented and declined are presented in Table 1.

\subsection{Aim 1: Consent Agreement}

Of 24 parents approached, 17 (71\%) agreed to participate. Four parent-dyads did not have valid contact information from the COMPL pool, leaving nine parent-dyads available in that group. Phone messages left for five of the remaining nine dyads were not returned after three contact attempts. The four remaining parent-dyads agreed to the genotyping. The next consecutive 15 parents of the ENROL group were approached for informed consent.

Parents consenting were 4 of the 9 infants (44\%) from the COMPL, and 13 of the 15 parents (87\%) from the ENROL group. Declining parents were those who did not return phone calls (COMPL) and those who verbally declined (ENROL). The research team chose to stop enrollment for the feasibility study after approaching 15 parents in the ENROL group because of the high rate of consent. Although in most cases both parents signed consent for genotyping, the mothers were the contacts who provided reasons for participating or declining. One mother asked about the ability to identify the infant from DNA and consented after being told that her infant's DNA would be destroyed after genotyping. The two mothers of newly enrolled infants (ENROL) who declined participation stated that they did not want to be involved in genetic research. Four mothers who agreed to participate explained that they liked contributing to 
research. Two of these mothers were employed in research activities. Other mothers $(n=13)$ stated that they wanted to help families dealing with infant GERD and two mothers did not provide a reason.

\subsection{Aim 2: Buccal Collection and Quality of DNA}

All 17 buccal samples were of sufficient quality to be analyzed from the two swabbings. No difficulties were encountered during the collection procedure. The younger infants sucked on the swabs, but were quiet during the collection. Older infants reached for the swabs as the RA approached their mouths, but were accepting of the procedure. Genotypes were obtained for all SNPs for all subjects. A single nucleotide polymorphisms (SNP) is a variation that occurs naturally in DNA. SNPs are commonly used as markers to facilitate the location of genes associated with specific behaviors or disease [24]. Table 2 presents a summary of SNPs genotyped and 16 minor allele frequencies (MAF) observed in the 17 subjects, along with the MAF listed in a public dbSNP, a catalog of common SNPs

(http://www.ncbi.nlm.nih.gov/projects/SNP/).

\section{DISCUSSION}

\subsection{Parental Consent}

Well over half (71\%) of parents allowed DNA collection and genotyping of their infants. While most parents enrolling in the massage study consented (ENROL), less than half of parents from the COMPL group agreed. Because parents in the COMPL group who did not participate in this feasibility could not be reached after three attempts we were unable to ascertain their reasons for declining to return our phone calls. However, the fact that these parents did not even respond to phone calls and e-mails suggests total disengagement from the research team. Conversely, parents in the ENROL group had current contact with the Research Coordinator (who assisted with recruitment) and the research team. This suggests that positive engagement with the research team may have influenced the decision to participate in the genetics study as reported by others [25,26].

In the ENROL group, mothers stated while enrolling in the intervention study that they did not like genetic research.

Mothers in parent dyads who agreed to participate either were supportive of research or wanted to help others. These altruistic reasons were similar to those voiced by mothers $(n=239)$ in a postpartum unit whose primary reason for participating was their belief that findings of the research would result in effective treatment for genetic disorders [17]. Adults who participated in genetic research also expressed that their willingness to participate was based on benefitting society and contributing to the common good $[27,28]$.

Table 1. Characteristics of parents of infants who consented and declined.

\begin{tabular}{lcc}
\hline Characteristic & Consented ( $\mathrm{n}=17)$ & Declined $(\mathrm{n}=7)$ \\
\hline Mean maternal age & 32.6 & 30.4 \\
Mean maternal education (years)** & 17.1 & 14.1 \\
Mean paternal age & 33.0 & 34 \\
Mean paternal education (years)* & 16.9 & 14.9 \\
\hline
\end{tabular}

${ }^{*} \mathrm{p}<0.05 ;{ }^{* *} \mathrm{p}<0.01$.

Table 2. Minor allele frequencies observed for 16 snps in sample $(n=17)$.

\begin{tabular}{|c|c|c|c|c|c|}
\hline Gene & $\mathrm{SNP}^{\mathrm{a}}$ & MAF Sample/MAF dbSNP & Gene & SNP & MAF Sample/MAF dbSNP \\
\hline $\mathrm{DRD}^{\mathrm{b}}$ & rs3758653 & $0.21 / 0.21$ & $\mathrm{COMT}^{\mathrm{d}}$ & rs 4680 & $0.32 / 0.43$ \\
\hline DRD4 & rs11246226 & $0.35 / 0.41$ & COMT & rs5993882 & $0.15 / 0.27$ \\
\hline DRD4 & rs1800443 & $0 / 0.01$ & COMT & rs740603 & $0.24 / 0.37$ \\
\hline 5-HTT ${ }^{\mathrm{c}}$ & rs3813034 & $0.5 / 0.43$ & СОМТ & rs4646312 & $0.21 / 0.48$ \\
\hline 5-HTT & rs8076005 & $0.15 / 0.22$ & $\mathrm{DAT}^{\mathrm{e}}$ & rs12516948 & $0.32 / 0.33$ \\
\hline 5-HTT & rs16965628 & $0.12 / 0.06$ & DAT & rs 40184 & $0.41 / 0.39$ \\
\hline 5-HTT & rs4325622 & $0.5 / 0.37$ & DAT & rs6350 & $0 / 0.07$ \\
\hline
\end{tabular}

a. SNP = single nucleotide polymorphisms; b. DRD4 = dopamine D4 receptor gene; c. 5-HTT = 5-hydroxytryptomine gene; d. COMT = Catechol-O-Methyltransferase gene; e. DAT = dopamine transporter gene. 
Only one mother in the COMPL group asked about tracing identity from DNA. Five parent-dyads requested one or two days to consider the study before consenting. It is possible that the fact that parents knew that the samples would be destroyed after collection and that only a few genes would be examined, lessened concerns about participating, although no-one stated this as a reason. The study was conducted by a research team from a large medical campus. Other research indicates that individuals are more likely to consent to genetic research when approached by a medical professional than a lay person [29], or medical personnel who they have determined are experts in their condition $[26,30]$. The fact that research was conducted through a large university may have indicated to the participants that members of the research team were experts in infant GERD and in genetics.

A barrier that had not been considered by the research team was education level of the parents. Education level of both mothers and fathers were higher in the group that consented versus the group that declined. Mean educational level of parents who consented was at the graduate level versus partial college for parents who declined. Other research has shown that individuals who are more highly educated (college) had more knowledge about genetic research than less educated individuals [31]. Perhaps having more knowledge of genetic research results in a more positive attitude toward participating in genetic studies.

\subsection{Aim 2: Quality of DNA}

The second aim was to establish that an adequate amount of high quality DNA could be obtained from infants from a cheek swab. The quality of the DNA obtained from two buccal swabs from all 17 infants was usable when genotyped. These findings are similar to the success reported by Erickson et al. [20] who used a buccal brush and Sziller et al. [32] who used buccal swabs.

The minor allele frequencies were similar to those listed in the major SNP database (dbSNP; http://www.ncbi.nlm.nih.gov/SNP/), indicating the quality of the data are consistent with what is already known about these SNPs. No issues arose from swabbing, and storage of the buccal specimens was more convenient than the temperature controlled requirements of many other biological specimens.

This study showed that many parents (71\%) are willing to have their infant's DNA genotyped for research, even for temperament and a condition such as GERD that is not life threatening. Specific reasons for declining contact with the research team were not provided by parents, resulting in responses from only two parents who expressed dislike of genetic research and this is a limitation. Another limitation is that fathers' opinion of genetic research was not obtained. Agreement to consent, however, was higher in parents who were highly educated, engaged with the research team, supported research, and wanted to help others.

Findings suggested that it is feasible to genotype DNA from infants using buccal swabs for four genes that have been found to be associated with temperament in infants [7-11]. Buccal swabbing can decrease the likelihood of discomfort and increase the parent's interest in participating. While the quality of DNA from buccal sampling was very good in this study, it was not compared to blood samples of Lehman et al. [21]. A comparison between buccal swabs and blood samples would have strengthened findings of this study.

\section{CONCLUSION}

Feasibility studies are important prior to conducting studies where issues like availability of subjects or quality of procedures for data collection are not known. Nurses conducting research involving parents of infants should be confident that parents in their target population are willing to participate in this type of research. Feasibility of collecting an adequate amount of DNA (for the specific genes of interest) and for the laboratory methods used for genotyping, also is important. Whether to use buccal swabs or blood samples for collection of DNA continues to undergo study. Given that blood samples are the "gold standard" for DNA collection in infants, more head to head studies are needed to confidently use buccal instead of blood samples.

\section{REFERENCES}

[1] Nelson, S.P., Chen, E.H., Syniar, G.M. and Christoffel, K.K. (1997) Prevalence of symptoms of gastroesophageal reflux during infancy. A pediatric practice-based survey. Archives of Pediatric and Adolescent Medicine, 151, 569572. http://dx.doi.org/10.1001/archpedi.154.2.150

[2] Sherman, P.M., Hassall, E., Fagundes-Neto, U., Gold, B.D., Kato, S., Koletzko, S. and Vandenplas, Y. (2009) A global, evidence-based consensus on the definition of gastroesophageal reflux disease in the pediatric population. American Journal of Gastroenterology, 104, 1278-1295. http://dx.doi.org/10.1038/ajg.2009.129

[3] Condino, A.A., Sondheimer, J., Pan, Z., Gralla, J., Perry, D. and O’Connor, J. (2006) Evaluation of infantile acid and nonacid gastroesophageal reflux using combined $\mathrm{pH}$ monitoring and impedance measurement. Journal of Pediatric Gastroenterology and Nutrition, 42, 16-21. http://dx.doi.org/10.1097/01.mpg.0000188008.66752.72

[4] Jordan, B., Heine, R.G., Meehan, M., Catto-Smith, A.G. and Lubitz, L. (2006) Effect of antireflux medication, placebo and infant mental health intervention on persistent crying: A randomized clinical trial. Journal of Paediatrics and Child Health, 42, 49-58. http://dx.doi.org/10.1111/j.1440-1754.2006.00786.x

[5] Moore, D.J., Tao, B.S., Lines, D.R., Hirte, C., Heddle, 
M.L. and Davidson, G.P. (2003) Double-blind placebocontrolled trial of omeprazole in irritable infants with gastroesophageal reflux. Journal of Pediatrics, 143, 219223. http://dx.doi.org/10.1067/S0022-3476(03)00207-5

[6] Neu, M., Corwin, E., Lareau, S.C. and MarchegianniHoward, C. (2011) A review of nonsurgical treatment for the symptom of irritability in infants with GERD. Journal for Specialists in Pediatric Nursing, 17, 177-192. http://dx.doi.org/10.1111/j.1744-6155.2011.00310.x

[7] De Luca, A., Rizzardi, M., Buccino, A., Alessandroni, R., Salvioli, G.P., Filograsso, N. and Dallapiccola, B. (2003) Association of dopamine D4 receptor (DRD4) exon III repeat polymorphism with temperament in 3-year-old infants. Neurogenetics, 4, 207-212. http://dx.doi.org/10.1007/s10048-003-0146-z

[8] Ebstein, R.P., Levine, J., Geller, V., Auerbach, J., Gritsenko, I. and Belmaker, R.H. (1998) Dopamine D4 receptor and serotonin transporter promoter in the determination of neonatal temperament. Molecular Psychiatry, 3, 238-246. http://dx.doi.org/10.1111/j.1601-183X.2010.00669.x

[9] Kim, S.J., Kim, Y.S., Lee, H.S., Kim, S.Y. and Kim, C.H. (2006) An interaction between the serotonin transporter promoter region and dopamine transporter polymorphisms contributes to harm avoidance and reward dependence traits in normal healthy subjects. Journal of Neural Transmission, 113, 877-886. http://dx.doi.org/10.1007/s00702-006-0444-3

[10] Posner, M.I. and Rothbart, M.K. (2009) Toward a physical basis of attention and self-regulation. Physics of Life Reviews, 6, 103-120. http://dx.doi.org/10.1016/j.plrev.2009.02.001

[11] Sheese, B.E., Voelker, P., Posner, M.I. and Rothbart, M.K. (2009) Genetic variation influences on the early development of reactive emotions and their regulation by attention. Cognitive Neuropsychiatry, 14, 332-355. http://dx.doi.org/10.1080/13546800902844064

[12] Arain, M., Campbell, M.J., Cooper, C.L. and Lancaster, G.A. (2010) What is a pilot or feasibility study? A review of current practice and editorial policy. BMC Medical Research Methodology, 10, 67. http://dx.doi.org/10.1186/1471-2288-10-67

[13] Borry, P., Stultiens, L., Nys, H., Cassiman, J.J. and Dieridkx, K. (2006) Presymptomatic and predictive genetic testing in monors: A systematic review of guidelines and position papers. Clinical Genetics, 70, 374-381. http://dx.doi.org/10.1111/j.1399-0004.2006.00692.x

[14] Laegsgaard, M.M., Kristensen, A.S. and Mors, O. (2009) Potential consumers' attitudes toward psychiatric genetic research and testing and factors influencing their intentions to test. Genetic Testing and Molecular Biomakers, 13, 57-65. http://dx.doi.org/10.1089/gtmb.2008.0022

[15] Jenkins, M., Reed-Gross, E., Barfield, W.D., Prue, C.E. Gallagher, M.L., Rasmussen, S.A. and Honein, M.A. (2011) Qualitative assessment of study materials and communication strategies used in studies that include DNA collection. National Center on Birth Defects and Developmental Disabilities, Centers for Disease Control and Prevention, Atlanta, USA.
[16] Botkin, J.R. (2010) Informed consent for genetic research. Current Protocols in Human Genetics, Chap 1. http://dx.doi.org/10.1002/0471142905.hg0116s66

[17] Neidich, A.B., Joseph, J.W., Ober, C. and Ross, L.F. (2008) Empirical data about women's attitude towards a hypothetical pediatric biobank. American Journal of Medical Genetics Part A, 146, 297-304. http://dx.doi.org/10.1002/ajmg.a.32145

[18] Mathisen, B., Worrall, L., Masel, J., Wall, C. and Shepherd, R.W. (1999) Feeding problems in infants with gastro-oesophageal reflux disease: A controlled study. Journal of Pediatric Child Health, 35, 163-169. http://dx.doi.org/10.1046/j.1440-1754.1999.t01-1-00334.x

[19] Rasmussen, S.A., Lammer, E.J., Shaw, G.M., Finnell, R.H., McGhee Jr., R.E., Gallagher, M. and Murray, J.C. (2002) Integeration of DNA sample collection into a multi-site birth defects case-control study. Teratology, 66, 177-184. http://dx.doi.org/10.1002/tera.10086

[20] Erickson, S.W., MacLoed, S.L. and Hobbs, C.A. (2012) Cheek swabs, SNP chips, and CNVs: assessing the quality of copy number variant calls generated with subjectcollected mail-in buccal brush DNA samples on a high density genotyping microarray. BMC Medical Genetics, 13, 13-51. http://dx.doi.org/10.1186/1471-2350-13-51

[21] Lehmann, A.S., Hass, D.M., McCormick, C.L., Skaar, T.C. and Renbarger, J.L. (2011) Collection of human genomic DNA from neonates: A comparison between umbilical cord blood and buccal swabs. American Journal of Obstetrics and Gynecology, 204, 362, e1-e6.

http://dx.doi.org/10.1016/j.ajog.2010.12.013

[22] Anchordoquy, H.C., McGeary, C., Liu, L., Krauter, K.S. and Smolen, A. (2003) Genotyping of three candidate genes after whole-genome preamplification of DNA collected from buccal cells. Behavioral Genetics, 33, 73-78. http://dx.doi.org/10.1023/A:1021007701808

[23] Hoft, N.R., Stitzel, J.A., Hutchison, K.E. and Ehringer, M.A. (2011) CHRNB2 promoter region: Association with subjective effects to nicotine and gene expression differences. Genes, Brain and Behavior, 10, 176-185. http://dx.doi.org/10.1111/j.1601-183X.2010.00650.x

[24] Lewis, R. (2011) Human genetics: Concepts and applications. 10th Edition, McGraw Hill, New York.

[25] Saldana, S.N., Hooper, D.K., Froehlich, T.E., Campbell, K.M., Prows, C.A., Sadhasivam, S. and Glauser, T.A. (2011). Characteristics of successful recruitment in prospective pediatric pharmacogenetic studies. Clinical Therapeutics, 33, 2072-2081. http://dx.doi.org/10.1016/j.clinthera.2011.10.026

[26] Wilson, P.M., Brooke, F., Procter, S. and Kendall, S. (2012) The nursing contribution to chronic disease management: A case of public expectation? Qualitative findings from multiple case study design in England and Wales. International Journal of Nursing Studies, 49, 214.

[27] McQuillan, G.M., Pan, Q. and Porter, K.S. (2006) Consent for genetic research in a general population: An update on the National Health and Nutrition Examination Survey experience. Genetics in Medicine, 8, 354-360. http://dx.doi.org/10.1038/ejhg.2010.106 
[28] Peppercorn, J., Shapira, J., Deshields, T., Kroetz, D., Friedman. P., Spears, P. and Bertagnolli, M.M. (2012) Ethical aspects of participation in the database of genotypes and phenotypes of the National Center for Biotechnology Information. Cancer, 118, 5060-5068. http://dx.doi.org/10.1002/cncr.27515

[29] Wilde, A., Mitchell, P.B., Meiser, B. and Schofield, P.R. (2012) Implications of the use of use of genetic tests in psychiatry, with a focus on major depressive disorder: A review. Depression and Anxiety, 30, 1-9. http://dx.doi.org/10.1002/da.22000

[30] Barnoy, S., Ofra, L. and Bar-Tal, Y. (2012) What makes patients perceive their health care worker as an epistemic authority? Nursing Inquiry, 1, 128-133. http://dx.doi.org/10.1111/j.1440-1800.2011.00562.x

[31] Morren, M., Rijken, M., Baanders, A.N. and Bensing, J. (2007) Perceived genetic knowledge, attitudes toward genetic testing, and the relationship between these among patients with a chronic disease. Patient Educational Counseling Journal, 65, 197-204.

http://dx.doi.org/10.1016/j.pec.2006.07.005

[32] Sziller, I., Hupuczi, P., Normand, N., Halmose, A., Pupp, Z. and Witkin, S.S. (2006) Fas (TNFRSF6) gene polymorphism in pregnant women with hemolysis, elevated liver enzymes, and low platelets and in their neonates. Obstetrics \& Gynecology, 107, 582-587. http://dx.doi.org/10.1097/01.AOG.0000195824.51919.81 